\title{
The Use of Ready-Made Glasses Among Presbyopes in Selected Local Government Areas of Edo State, Nigeria
}

\author{
Ebeigbe* J. A and Uwagboe P. N \\ Department of Optometry, Faculty of Life Sciences, University of Benin, Benin City Nigeria. \\ * Correspondence: Jennifer.ebeigbe@uniben.edu; doi: https://doi.org/10.52417/njls.v11i1.26
}

\begin{abstract}
The use of ready-made glasses (RMG) has been reported to be common in developing or poor resource countries. This cross-sectional questionnaire study was undertaken to determine the prevalence of use of ready-made glasses among presbyopes in selected Local Government Areas of Edo State. Over 2000 closed ended questionnaire were distributed among adult males and females in churches, schools, government offices and market places. One thousand six hundred were collected back. Properly completed 1496 forms were analyzed using percentages and correlation coefficient. Level of significance was set at $p<0.05$. Male respondents made up $51.80 \%$ of the population while female respondents made up $48.20 \%$. The mean age of respondents was 57 ( \pm 1.2 ) years. A total of $66.80 \%$ of them had bought RMG. While $41.60 \%$ felt it met their visual need, $52 \%$ on the other hand, said there could be problems associated with the use of RMG. Some of the respondents $52 \%$ said they would not advice others to buy RMG from the roadside. There was no statistical difference in the use of RMG between males and females $(p<0.05)$. There was no statistically significant correlation between educational status and the use of RMG between the genders. There was also no statistically significant correlation between financial earnings and the use of RMG between the genders. The use of RMG appears to meet some of the need in eye care.
\end{abstract}

Keywords: Ready-made, glasses, refractive error, eyecare.

\section{Introduction}

Global estimate indicates that more than 2.3 billion people in the world suffers from poor vision due to refractive error and presbyopia out of which 670 million people are considered visually impaired because they do not have access to corrective treatment (WHO, 2014).

Refractive error is an error in the focusing of light by the eye and the frequent reason for reduced visual acuity. Uncorrected distance refractive error is the most common cause of visual impairment and the second most common cause of blindness in the world (Bekibele and Gureje, 2008). Uncorrected refractive errors and presbyopia can hinder performance at school, reduce employability, productivity and generally impair quality of life (Patel and West, 2007; Keay et al., 2010; Ebeigbe and Obahiagbon, 2012). The correction of refractive errors with appropriate glasses is among the most cost-effective intervention in health care (Naidoo et al., 2006; Bourne, 2007).

In most developing countries, most of the health care centers, including eye clinics are located in urban areas. People who live in rural areas are forced to get care from the urban areas and this add to the cost of the spectacles (Brian et al., 2006; Ebeigbe and Kio, 2010). Usually, the frame may not fit properly and the optical center may not be properly placed. This can cause headache or eye strain (Laviers et al., 2012). They are also made with the power in each eye as the same, and so are not ideal for people who have different prescriptions in each eye. Although they are frequently made for reading, prescription for myopia and hyperopia are sometimes found. None are made to correct astigmatism (Mahmoona et al., 2016).

Christopher et al. (2012) reported that RMS are suitable for the majority of individuals with uncorrected refractive error. The study provided further evidence for the use of RMS where custom spectacles are inaccessible to those in need. Dandona et al. (2002) found that a significant proportion of people discontinued spectacle use due to reasons suggesting poor quality of refractive service.

Ready-made glasses have the advantages of been readily available and are inexpensive. However, the disadvantages are that the frames are mass produced and may not fit well. Manufacturers assume that the distance between the eyes is the same for all patients, so the lenses may not be correctly aligned with one's eyes. They contain a simple prescription, which is unlikely to be exactly right for one's eyes. They have the same lens for both eyes but many people require a slightly different lens for both eyes. Finally, they do not give as much comfort or better vision as custom made glasses (Brian et al., 2006).

The purpose of this study was to determine the prevalence of use and the reasons for use of ready-made glasses among Presbyopes in selected local government areas of Edo south.

\section{Materials And Method}

This was a questionnaire-based study. Six Local Government Areas (LGAs) in Edo South Senatorial District were selected by convenient sampling. They are Orhionmwon, Oredo, Ikpoba-Okha, Uhunmwonde, Egor and Ovia North West. Over 2000 questionnaire were distributed among Presbyopes in different locations including Schools, Government Offices, Churches and Market places in these LGAs. The returned questionnaires were 1600 , of which 1496 were completely and properly filled; these were the ones that were analyzed for the study. Inclusion criteria were adults from the age of 35 years and above as well as those who could communicate in English Language or Pidgin English. Informed consent was given by participants after the nature and purpose of the study was explained to them. Ethical approval was obtained from the Department of Optometry Research Ethics Committee. The returned questionnaires were analyzed using percentages and Spearman's correlation coefficient. The results are presented in tables and charts. A $p$-value $\leq 0.05$ was considered to be statistically significant.

\section{Results}

There were $775(51.80 \%)$ males and $721(48.20 \%)$ females among the respondents. The mean age of the respondents was $57( \pm 1.2)$ years. Most of the respondents $(36.36 \%)$, had secondary school 
education as shown in Table 1. Responses to the questionnaires are presented in Figure 1. This shows that about $67 \%$ of them have had their eye examined in a clinic, majority of whom were females. About sixty-five percent of the sampled population had been recommended for glasses at one time or another. However, only $42.7 \%$ of them obtained their recommended glasses from the clinic.

Table 1: Demography of Respondents

\begin{tabular}{lcccccc}
\hline Variables & \multicolumn{2}{c}{ Male } & \multicolumn{2}{c}{ Female } & \multicolumn{2}{c}{ Total } \\
& No & $\%$ & No & $\%$ & No & $\%$ \\
\hline Sex & 775 & 51.8 & 721 & 48.2 & 1496 & 100 \\
\hline Age Brackets & & & & & & \\
\hline $35-40$ & 30 & 3.87 & 49 & 6.80 & 79 & 5.28 \\
$41-45$ & 76 & 9.81 & 70 & 9.71 & 146 & 9.76 \\
$46-50$ & 200 & 25.81 & 88 & 12.21 & 288 & 19.25 \\
$51-55$ & 199 & 25.67 & 193 & 26.76 & 392 & 26.20 \\
$56-60$ & 200 & 25.71 & 207 & 28.71 & 407 & 27.21 \\
61 and above & 70 & 9.03 & 114 & 15.81 & 184 & 12.30 \\
\hline Educational status & & & & & & \\
\hline Primary & 174 & 22.45 & 300 & 41.61 & 474 & 31.70 \\
Secondary & 323 & 41.68 & 221 & 30.65 & 544 & 36.36 \\
Tertiary & 278 & 35.87 & 200 & 27.74 & 478 & 31.93 \\
\hline
\end{tabular}

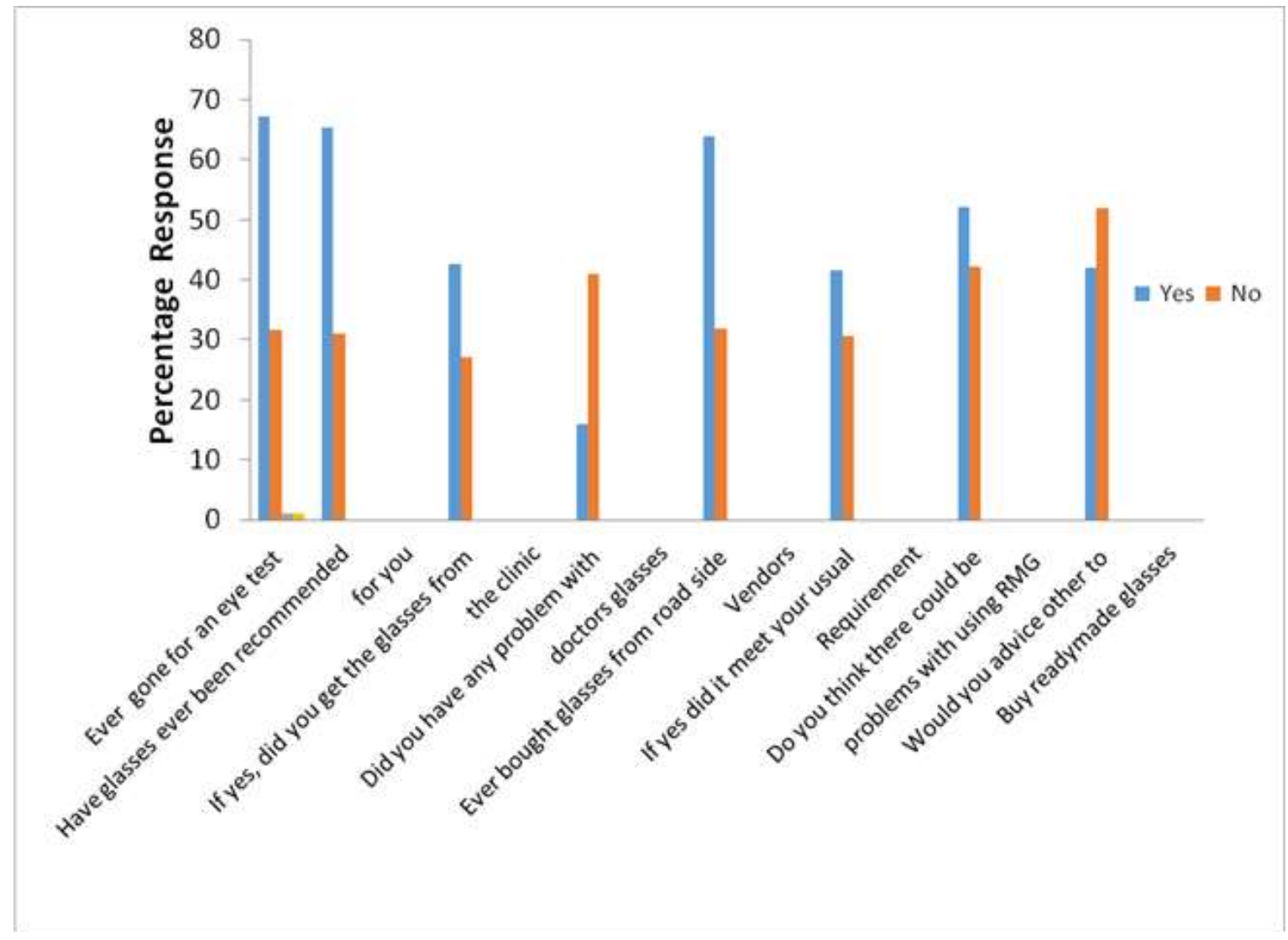

Figure 1: Participants' responses to questions asked

Among the respondents, $66.80 \%$ admitted to buying RMG from the road side. Some of them $(41.60 \%)$, were of the opinion that the RMG met their visual requirement. Others $(52 \%)$ were of the opinion that there could be problems associated with the use of RMG. Fifty- two percent (52\%) of the respondents said they would not advice others to buy RMG from along the road side. Table 2 shows reasons given by the respondents for the use of RMG. The main reason being that it costs less than the custom-made glasses
(48.32\%); this was followed by time saved from waiting long at the clinic to see the doctor $(25.20 \%)$ and the convenience of buying RMG from the roadside, (16.71\%). Figure 2 shows the monthly financial earning capacity of the respondents. Some $33 \%$ of respondents, earned less than a hundred thousand naira while only $2 \%$ of them earned two hundred thousand naira and above. The difference between male and female use of RMG was not statistically significant $p>0.05$. There was no statistically 
significant correlation $(r=-0.02, p=0.90)$ between the educational status and the use of RMG between the genders. Correlation between financial earning and use of RMG was also not statistically significant $(r=-0.20, p=0.24)$ between males and females.

Table 2: Reasons given for purchase of ready-made glasses

\begin{tabular}{lcccccc}
\hline Reasons & \multicolumn{2}{c}{ Male } & \multicolumn{2}{c}{ Female } & \multicolumn{3}{c}{ Total } \\
& No & $\%$ & No & $\%$ & No & $\%$ \\
\hline Convenience & 129 & 16.65 & 121 & 16.78 & 250 & 16.71 \\
Cost less & 468 & 60.35 & 255 & 35.37 & 723 & 48.32 \\
Avoid wait at clinic & 112 & 14.45 & 265 & 36.75 & 377 & 25.20 \\
Same as Doctor's prescription & 66 & 8.52 & 80 & 11.10 & 146 & 9.76 \\
\hline Total & 775 & 100 & 721 & 100 & 1496 & 100 \\
\hline
\end{tabular}

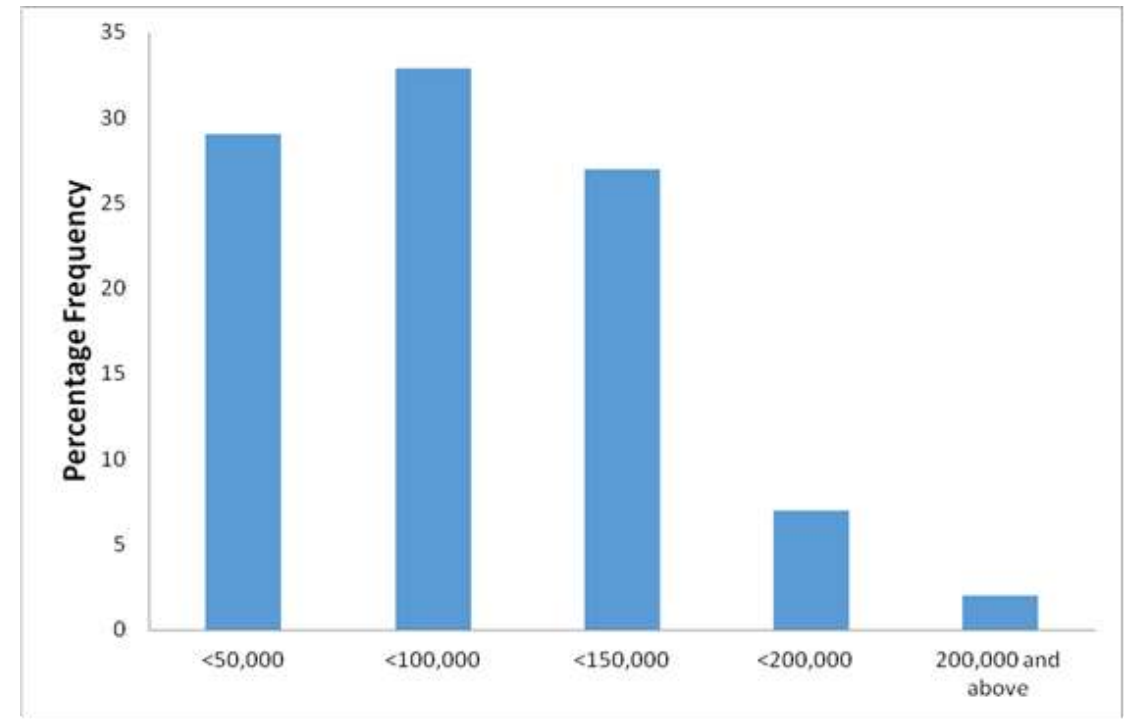

Figure 2: Monthly Financial earnings of the respondents

\section{Discussion}

Glasses are the most common means of correcting refractive errors. Glasses are usually prescribed and dispensed with corrective lenses that give the best vision and are comfortable. Custom made glasses are the gold standard. This is because they are made specifically to meet individual needs. Although they are more expensive, they are essential in certain cases when an individual requires different power of lenses in each eye or when a patient is astigmatic and needs cylinders in their lens prescription. However, those who do not have astigmatism or have a low level of it and have no difference or insignificant difference between the left and right eyes can be corrected with RMG. This could be the reason why a number of respondents reported that RMG met their visual needs.

Although a high proportion of respondents use RMG because they are cheaper than custom made gasses, there was no statistically significant correlation between financial earnings and use of RMG among the respondents.

The popular belief that only illiterate people or non-educated people buy RMG from the roadside is not supported by this study because, there was no statistically significant correlation between educational status and use of RMG among the respondents.

Generally, people are often pressed for time so, factors like convenience and avoidance of long wait at the doctor's office might be better motivation for use of RMG among individuals. Despite the reported disadvantages of RMG, which include being a "one size fits all", the frame not fitting properly, the optical center not being properly placed which can cause headache or eyestrain, they are also made so that the power in each eye is the same and so are not ideal for people who have different prescriptions in each eye, individuals still subscribe to the use of these glasses. However, studies in Cambodia and India have reported that up to $70-90 \%$ of children with uncorrected refractive errors could benefit from RMG (Ramke et al., 2008) and (Priya et al., 2016).

A number of studies have shown that women are more careful about their eye care than men. Fotouhi et al., (2006) reported that women in Iran were more likely to seek eye care services than men. Similarly, Palagyi et al., (2008) reported that women in Timor-Leste with either low vision or blindness were more likely to seek treatment than men. Schaumberg et al., (2000), Morales et al., (2010) and Bylsma et al., (2004) also reported that women tended to have eye examinations more frequently than men. However, this study observed that gender did not influence the purchase of readymade spectacle as there was no correlation between the gender and the use of RMG.

Majority of the respondents gave cost as their reasons for buying readymade glasses. It can therefore be inferred that cost is the major reason why people buy readymade spectacle agreeing with (Wubben et al., 2014) who reported that financial constraint is the most common barrier to accessing presbyopic care. Another study by (Robin et al., 2004) stated that, in developing and developed 
nations, finances can definitely influence the utilization of ophthalmic health care.

Although majority of the respondents fell between income earning levels of $\$ 50,000$ and $\$ 100,000$, there was no correlation between financial status and the use of RMG in this study. Other workers have reported a relationship between financial status and use of eyecare. Srinivas et al. (2009) stated that individuals with optional vision insurance and those with higher income levels were more likely to use eye care services. Another study by Robin et al. (2004) reported that the odds of using eye care increased significantly with higher the income of the subject. Similar study by Schaumberg et al. (2000) found that women with annual income exceeding US $\$ 50000$ were twice as likely to have an eye examination within two years when compared with women with lower income. Meanwhile, Priya et al. (2016) were of the opinion that affordability of optometric services should be considered within a broader context than the cost of the spectacle because, even a free pair of spectacles could prove to be unaffordable, if the patient has to return to the clinic many times in order to collect it. Results from this study has shown that there was no significant correlation between educational status and use of RMG. In contrast a study carried out by Fotouhi et al. (2006), reported that the likelihood of seeking eye care in Iran was associated with higher levels of education. This relationship was attributed to greater knowledge and therefore more reasonable behavior. It was also presumed to be due to the fact that educated people are members of the higher socio-economic class, thus may have greater access to eye care services and also find them more affordable. Ramke et al. (2008) reported a positive association between education and eye care use; the higher the level of education, the more likely and timely eye examinations are performed, and the less likely that blindness will occur. In similar studies Orr et al. (1999) and Ramke et al. (2009) found that people with higher education were significantly more likely to seek eye care services and this was attributed to the fact that most people with higher education were higher earners and could afford health care services.

More than half of the respondents $(52 \%)$ in this study were of the opinion that there could be problems arising from the use of RMG. This is in agreement with the study by Elliot and Green, (2012), where they reported a significant number of irregularities associated with the use of RMG. In a study to determine whether the optical quality of near-vision ready-made spectacle reached the quality assurance levels required by the international standard. Elliot and Green, (2012) reported that there was a large prevalence of significant amount of induced horizontal and vertical prisms in higher powered near-vision RMG such as +3.50DS. Given that the need for high powered RMG indicates the presence of hyperopia and/or age-related eye disease in addition to presbyopia, it may be appropriate to restrict the sale of RMG to optical powers of +1.00 to $+2.50 \mathrm{DS}$, which will contain much fewer errors.

Elliot and Green, (2012) also recommend that manufacturers use a centration distance for near-vision RMG that is similar to an average near (and not distance) inter-pupillary distance. In a similar study by Du Toit et al., (2007) it was reported that most spectacle wearers would comfortably tolerate $<$ or $=0.5$ delta vertical $<$ o $r=1.0$ delta base out or $<$ or $=1.0$ delta base in induce prism. From this study, a guide to the maximum interpupillary distance/optical center distance disparities likely to be comfortably tolerated with varying spectacle powers was formulated. It was concluded that power up to +/-1.50DS were unlikely to have sufficient lens de-centration to cause discomfort. The present study supports the feasibility of using readymade spectacles in low resource settings even though optical center distance may be different from the inter-pupillary distance of the user.

The advantages of RMG are that they are less expensive, can be dispensed immediately in clinics and require less time to dispense. However, the drawbacks to RMG are that they require a large inventory of frames in different sizes, colors and shapes, each with a range of power lenses. They are only suitable if the prescription in both eyes is the same and lenses are seldom available in powers of over $\pm 3.50 \mathrm{DS}$. Despite the disadvantages, some uses have been found for RMG especially in environments where access to custom made glasses is difficult or restricted by finance. However, whether RMG or custom-made glasses, both should only be dispensed by trained personnel, based on appropriate refractive technique undertaken by a competent eye care Practitioner.

\section{Acknowledgement:}

The authors wish to thank the Chairmen of the Local Government Areas visited, for their kind support.

\section{Conflict Of Interest: None.}

\section{References}

Bekibele, C.0. and Gureje, 0. (2008). Self-reported visual impairment and impact on vision-related activities in an elderly Nigerian population: report from the Ibadan study of ageing. Ophthalmic Epidemiology.15(4):250256.

Bourne, R. R. (2007). Uncorrected refractive error and presbyopia: accommodating the unmet need. British Journal of Ophthalmology. 113:723-727.

Brian, G., du Toit, R., Wilson, D and Ramke, J. (2006). Affordable readymade spectacles for use in blindness preventation programmes: setting standard of quality. Clinical and Experimental Ophthamology. 34: 722-724.

Bylsma, G.W., Le, A., Mukesh, B.N., Taylor, H.R., Mccarty, C.A. (2004). Utilization of eye care services by Victorian likely to benefit from eye care. Clinical and Experimental Ophthalmology. 32: 573-577.

Christopher, B. C., Villanta, A. C., Gandhi, M., Ivudman, D. S and Keay, L. (2012). Visual function after correction of distance refractive error with readymade and custommade spectacles: A Randomize Clinical Trail. Journal of ophthalmology. 119 (10): 2014-2020.

Dandona, R., Dandona, L., Kovai, V., Giridhar, P., Prasad, M. V and Srinivas, M. (2002). Population base study of spectacle use in southern India. Indian Journal of Opthalmology. 200 (50): 145-55.

Du Toit, R., Ramke, J and Brian, G. (2007). Tolerance to prism induced by readymade spectacles: Setting and using a standard Optometry and Vision Science. 84(11):10531059.

Ebeigbe, J. A and Kio, F. E. (2010). Refractive error in rural community in Edo-state. Afscope. 1 (2):52-55.

Ebeigbe, J. A and Obahiagbon, E. A. (2012). Correction of presbyopia among an adult Nigerian population. 
Nigerian Research Journal of Clinical Science. 2 (1): $52-$ 57.

Elliot, D.B and Green, A. (2012). Many readymade spectacles fails the required standards. Optometry and Vision Science. 89(4):446-451.

Fotouhi, A., Hashemi, H and Mohammed, K. (2006) Eye care utilization patterns in Tehran population: A population based cross-sectional study. British Journal of Ophthalmology. 6: 4-12.

Keay, L., Gandhi, M., Brandy, C., Mathur, U and Munoz, B. (2010). A randomize clinical trial to evaluate readymade spectacle in adult population in India. International Journal of Epidemology. 39: 877-88.

Laviers, H. R., Omar, F., Jecha, H., Kassim, G and Gilbert, C. (2010). Presbyopic spectacle coverage, willingness to pay for near correction and the impact of correcting uncorrected presbyopia in adults in Zanziber East Africa. Investigative Ophthalmology and Vision Science. 51: 1234-1241.

Mahmoona, M., Muhammmad, A. K., Madiha, T. (2016).Use of readymade spectacles to meet visual needs in a lowincome population. Ophthalmology Pakistan. 4(8): 28:31.

Morales, L.S., Varma, R., Paz, S.H., Lai, M.Y., Mazhar, K. Andersen, R.M and Azen, S.P. (2010). Self-reported use of eye care among Latinos: Los Angeles Latino Eye Study. Ophthalmology. 117: 207-215.

Naidoo, K., Savage, B and Westerfall, B. (2006 ). Creating a sustainable spectacle delivery solution. Vision. 12:122128.

Orr, P., Barron, Y., Schein, O.D., Rubin, G.S., West, S.K. (1999) Eye care utilization by older Americans. Ophthalmology.106:905-909.

Palagyi, A., Ramke, J., du Toit, R and Brian, G. (2008). Eye care in Timor-Leste: a population-based study of utilization and barriers. Clinical and Experimental Ophthalmology.36: 47-53.
Patel, I and West, S.K. (2007). Presbyopia: prevalence, impact and interventions. Community Eye Health Journal. 20: 40-41.

Priya, M., Kaushik, M., Evans, J and Gilbert, C. (2016) Spectacle wearing in children randomized to readymade or custom spectacles and potential cost savings to programmes: study protocol for a randomized controlled trial. $B M C$ Ophthalmology. 17:36. 1-8.

Ramke, J., Palagyi, A., DuToit, R and Barry, G. (2009). Applying standards to readymade spectacles used in lowresource countries. Optometry and Vision Science. 86(9):1104-1111.

Ramke, J., Palagyi, A., DuToit, R. and Brian, G. (2008). Using assessment of willingness to pay to improve Cambodian spectacle service. British Journal of Ophthalmology. 92: 170-174.

Robin, A., Nirmalayan, P., Ramasamy, K., Rengappa, R., Katz, J., Tielsch, J., Ravilla, D and Friedman, M. (2004). The utilization of eye care services by persons with glaucoma in rural South India. Trans American Ophthalmology Society. 102:47-52.

Schaumberg, D., Christen, W., Glynn, R and Buring, J. (2000) Demographic predictors of eye care utilization among women. Med Care. 38:638-646.

Srinivas, M., Krishnaiah, S., Khanna, R.C and Rao, G.N. (2009). Prevalence and risk factors for refractive errors in the South Indian adult population: The Andhra Pradesh eye disease study. Clinical Ophhtalmology. 3(1):17-27.

World Health Organization. (n.d.). Blindness: Vision 2020-Global initiative for elimination of avoidable blindness. Retrieved May 31, 2014, from World Health Organization: http//www.who.int/mediacentre/factsheets/Fs213/en/

Wubben, T.J., Guerrero C.M., Salum, M., Wolfe, G.S., Giovannelli, G.P and Ramsey, D. J. (2014). Presbyopia: a pilot investigation of the barriers and benefits of near visual acuity correction among a rural Filipino population. BMC Ophthalmology.33 (5):597-603. 